\title{
POESIA FEMININA: CONSIDERAÇÕES SOBRE O SLAM NA CULTURA CONTEMPORÂNEA
}

\author{
WOMAN POETRY: SLAM CONSIDERATIONS ON CONTEMPORARY CULTURE
}

\author{
Lovani Volmer ${ }^{1}$ \\ Daniel Conte ${ }^{2}$ \\ Suzana da Silva Souza ${ }^{3}$
}

\begin{abstract}
RESUMO: $O$ presente trabalho visa tecer uma relação entre poesia e protagonismo feminino a partir da discussão de um recente movimento sociocultural denominado Slam. Para tanto, são apresentados, à luz das teorias de autores como Bachelard, Candido, Cassirer e Zumthor, os elementos fundamentais que compõem o referido movimento e que o articulam à contemporaneidade, enfocando seu papel na valorização do processo de autoria das mulheres poetas e no desvelamento de vozes historicamente estabilizadas à margem da sociedade.
\end{abstract}

Palavras-chave: Poesia; cultura; Slam; poetas.

ABSTRACT: The present work aims to weave a relationship between poetry and feminine protagonism from the discussion of a recent sociocultural movement called Slam. Therefore, in the light of the theories of authors such as Bachelard, Candido, Cassirer and Zumthor, the fundamental elements that compose this movement and that articulate it to contemporaneity are presented, focusing their role in valuing the process of women poets' authorship and unveiling of historically stabilized voices on the fringes of society.

Keywords: Poetry; culture; Slam; women poets.

\section{Considerações iniciais}

Da relação do ser humano com a linguagem resultaram infinitas materialidades que causaram, e ainda causam, impactos na constituição histórica das sociedades. Parte significativa do que denominamos ações humanas, como a invenção da escrita e as narrativas constituintes das culturas, por exemplo, tornaram-se possíveis devido ao fenômeno da linguagem e de seu sistema operatório. Por meio deles, conhecemos mundos, pessoas e objetos. A linguagem pode valer-se, contudo, da aliança com outras ciências, outros saberes e, assim, materializar universos fabulados, que constituem processos de subjetivação dos atores sociais. É, também, pela ordem

\footnotetext{
${ }^{1}$ Doutora em Letras, ênfase em Leitura e Linguagens, pela UCS/Uniritter. Professora dos cursos de Letras e Pedagogia e do Mestrado Profissional em Letras da Universidade Feevale.

${ }^{2}$ Bolsista de Produtividade em Pesquisa do CNPq. Doutor em Literatura Brasileira, Portuguesa e Luso-africana, Mestre em Literatura Comparada. Professor permanente e pesquisador da Universidade Feevale, atuando no PPG em Processos e Manifestações Culturais e nos Mestrados Profissionais em Letras e Indústria Criativa.

${ }^{3}$ Mestre em Letras pela Universidade Feevale.
} 
da linguagem que se constrói o diálogo inter-imagético, que possibilita a tessitura de registros, do mundo como paradigma do real, a evidência dos problemas mundanos ou a elaboração enfática de sentimentos e anseios.

O texto literário conforma, ainda, o processo de redimensionamento do código linguístico, bem como é capaz de desvelar o olhar sobre fatos e subjetivações históricas ou, também, elevar a um patamar de audibilidade social sujeitos e narrativas historicamente relegados às coxias do imaginário social. No espaço contemporâneo, muitos são os movimentos e bandeiras sociais que têm provocado importantes reflexões acerca de conceitos fossilizados. Citamos, como exemplo, discussões acerca de quais materialidades artísticas da cultura podem ser legitimadas como literatura no sistema; da importância dos efeitos de sentido da obra literária, tanto em prosa quanto em verso; ou, ainda, do lugar que o texto literário ocupa no ordinário cotidiano.

Mesmo que a cultura seja direito e necessidade humanos, ainda existem grupos que precisam se colocar em um espaço enunciativo de evidência. Nessa ordem, o campo das artes relaciona-se, também, aos processos culturais, os quais trazem inscritas muitas temáticas materializadas, por exemplo, pelo poema, de onde emergem não só uma constituição estética do objeto, mas, também, uma ordem memorial do imaginário.

Esta, por sua vez, é uma das faces mais relevantes do movimento que condensa todos os tópicos que serão apresentados ao longo deste estudo: o Slam. A arte, sabemos, é um fundamental meio de expressão. Nesse sentido, visamos apresentar os principais componentes do Slam, enfocando as modalidades que privilegiam a poeticidade de autoria feminina, por meio das quais a expressão lírica ocorre democrática e publicamente. Junto à abordagem desse recente movimento sociocultural, apresentamos a concepção da arte como benefício e necessidade humanos, a partir de pesquisa básica bibliográfica, com a base teórico-crítica que envolve autores como Umberto Eco, Ernst Cassirer, Gaston Bachelard, Paul Zumthor, entre outros.

\section{A relação da palavra com a cultura, o pensamento e o sujeito}

Se Fedro conduziu Sófocles para fora da cidade - espaço em excesso racional - cruzando suas portas para incorporar às palavras a paisagem, e se as margens do Ilisso serviram de palco para a animação metamórfica da palavra, isso não é em si o mais importante. Significativo é o estado da matéria. A palavra é em si matéria, suplemento físico do que em si está adormecido. Não significado em tempo. Esse estrato vocálico - sim, vocálico - engendra uma diversidade imensurável de significantes. O que é colocado por ele sedimenta-se como [des]habitação de um espaço possível para, de imediato, traçar o caminho inverso. Desfazimento inaudito do Outro. Sociedades foram erguidas sobre a palavra. Outras marginaram a ossatura de sua gente. $\mathrm{O}$ Império Romano começou sua erosão paulatina em um contexto no qual não haviam palavras suficientes para habitar tamanha extensão, e o pergaminho tornara-se raridade naquele horizonte.

O certo é que desde os primórdios de sua existência, o ser humano busca se fazer entender por meio da linguagem, faculdade aprimorada ao longo da vida. Tanto em seu aspecto 
individual quanto coletivo, ela não possui somente a finalidade comunicacional, como bem estudam os linguistas. As correntes teóricas a respeito de suas funções apontam, inevitavelmente, aos meandros da comunicação. Nessa percepção, podemos tratar da linguagem como um fenômeno capaz de originar outros de indubitável relevância ou apontar novamente para si própria, o que conhecemos, nesse caso, como metalinguagem. De modo geral, é possível, ainda, afirmarmos que

a ciência teórica permanece sempre a mesma, em sua natureza e essência, seja qual for o objeto a que se refira, assim como a luz solar permanece sempre a mesma, por mais numerosos e diversos que sejam os objetos por ela iluminados. Algo idêntico podemos dizer de qualquer forma simbólica da linguagem, assim como da arte ou do mito, já que cada uma delas é uma espécie à parte do ver e abriga, em seu último, um foco de luz próprio e peculiar (CASSIRER, 1992, p. 25).

Por meio desse cotejamento, visualizamos todas as áreas mencionadas pelo autor como maiores do que os objetos por elas analisados. Da mesma forma, o ato de ver nada mais é do que as múltiplas maneiras a partir das quais compreendemos o mundo e lidamos com os fenômenos, cujas origem e permanência transcendem, não raro, à sua aplicabilidade.

Ao tomarmos a linguagem como fenômeno, levamos em conta a sua capacidade de designar e manifestar uma verdadeira imensidão de elementos percebidos na realidade. $\mathrm{O}$ uso da palavra o fazemos para nomear, diferenciar, caracterizar, segregar ou agregar, dentre tantas outras ações, que visam a interpretar o mundo, a realidade e o conjunto sígnico do imaginário. Definimos, consoante Cassirer (1992), o que pode ser transitório ou permanente; o que é objeto ou processo; a raiz da formação da linguagem como um fato pontual, mas deixamos à parte a noção de que é a linguagem que estabelece todas essas problemáticas, provocando uma grande crise espiritual, em que ocorrem dicotomias entre o transitório e o permanente, entre o ser e sua projeção ao longo do tempo, entre o real e o imaginado.

Destarte, uma das problemáticas que emergem da relação entre linguagem e ser humano é que as práticas sociais de cunho excludente, violento ou discriminatório podem ser naturalizadas por meio da própria linguagem utilizada em discursos que geram a segregação social, apontando, assim, para uma espiral esquizofrênica da realidade, como observa Rancière (2014). Se considerarmos Fanon, um "homem que possui a linguagem possui, em contrapartida, o mundo que essa linguagem expressa e que lhe é implícito. Já se vê onde queremos chegar: existe na posse da linguagem uma extraordinária potência" (FANON, 2008, p. 34). Essas palavras do autor evidenciam um fato significativo: a existência torna-se fluída no espaço da realidade a partir do ato enunciativo, uma vez que traz em si, pela linguagem, o aspecto memorial e mimético da condição humana. Salientamos que essa potência não converge somente à dominação social, ao ato de colonizar narrativamente o outro, de convencêlo a adotar valores externos aos seus, mas é a engrenagem que permite a reflexão acerca dessa problemática e dos demais temas emergentes no espaço do contemporâneo.

Considerando as nuances sistêmicas da linguagem, suas funções são perceptíveis em diferentes níveis de predominância da representação social e, na grande maioria das situações, agem de modo harmonioso e integrado, pois tal "feixe de funções não é uma simples 
acumulação: constitui uma hierarquia de funções e é sempre muito importante saber qual a função primária e quais as funções secundárias" (JAKOBSON, 2007, p. 18). Compreendendo que as estruturas da linguagem revelam funções diversas e com importâncias diversas, percebemos a linguagem como um poderoso instrumento político, espiritual e afetivo, posto que, por meio do signo, mostramo-nos ao outro, narramo-nos ao outro, narramos o mundo e a realidade ao outro e, ainda, injustamente, narramos o outro. $\mathrm{O}$ poder contido nos redutos da linguagem pressupõe que este

vínculo originário entre a consciência linguística e a mítico-religiosa expressase, sobretudo, no fato de que todas as formações verbais aparecem outrossim como entidades míticas, providas de determinados poderes míticos, e de que a Palavra se converte numa espécie de arquipotência, onde radica todo o ser e todo acontecer (CASSIRER, 1992, p. 64).

Narrar os processos que culminam na constituição histórica de um sujeito é, nesse sentido, também uma maneira deliberada de tomar posse e dominar - por ação da arquipotência da palavra - o seu modo de estar na sociedade e, por conseguinte, no mundo. No entanto, consoante Jakobson (2007), admitindo-se a força da linguagem e seu poder mítico sobre a sociedade, é possível identificar a mútua relação entre palavra e cultura, de modo que a linguagem seja configurada como parte integrante da prática social, podendo redimensionar o caráter memorial e imagético dos seus atores.

A mesma linguagem, por outro lado, que serve de instrumento para tais feridas sociais, pode ser uma potente ferramenta para promover ações positivas e humanizadoras, como, por exemplo, a manifestação poética denominada Slam, movimento que coloca o sujeito e sua voz no centro da enunciação performática do contemporâneo. A expressão do pensamento a partir da palavra admite uma outra relação, tão importante quanto a da cultura e a da linguagem, pois, conforme Cassirer (1992), pensamento e expressão verbal são comumente tidos como uma coisa só e feitos da mesma matéria, uma vez que o coração pensante e a língua falante pertencem um ao outro, obrigatoriamente.

Ao afirmarmos que a linguagem exerce múltiplas funções, dentre elas, a de designar a constituição e a estrutura do mundo, entendemos que a identidade essencial

entre a palavra e o que ela designa torna-se ainda mais evidente se, em lugar de considerar tal conexão do ponto de vista objetivo, a tomamos de um ângulo subjetivo. Pois também o eu do homem, sua mesmidade $\mathrm{e}$ personalidade, estão indissoluvelmente unidos com seu nome, para o pensamento mítico. O nome não é nunca um mero símbolo, sendo parte da personalidade de seu portador; é uma propriedade que deve ser resguardada com o maior cuidado e cujo uso exclusivo deve ser ciosamente reservado (CASSIRER, 1992, p. 68)

O excerto aponta para a relação mítica de pertencimento entre sujeito e signo, concretizada pelo nome e a história que esse suporta em si. É o nome que personifica o sujeito, torna-o único, identifica-o no mundo e no seio do lar. É a sua carga gratuita e eterna, atribuída 
e proferida por outrem com expectativas e projeções ocultas. É a evidência maior de que humanidade e palavra estão fadadas a coexistirem na fluidez temporal da existência.

O uso da linguagem é, pois, inerente à vida em sociedade. As ideias que não encontram espaço na vida pragmática ou que habitam os espaços próprios do imaginário social - os espaços da divagação, do sonho e do humor - têm vez, entretanto, na linguagem literária, que desvela e pinta os modos de determinada realidade e de determinado tempo. Para Eco (2011), a literatura, ainda, mantém a língua como patrimônio coletivo e é capaz de criar identidades e comunidades. É a necessidade de fabular que impulsiona o ser humano à criação, à invenção e à renovação das narrativas de si e do mundo. Dessa forma, compreendendo a literatura como necessidade, entendemos também que ela deve ser um direito de todo ser humano. Em uma pertinente reflexão, Eco (2011) assegura que os indivíduos cujas ações resultam em delitos não se tornaram as pessoas que são ao acaso, mas porque tiveram negado o acesso àqueles bens culturais, como a educação, os livros e a discussão construtiva de problemas. Ou, de modo mais simples, porque foram excluídos do âmbito literário, de fabulação, tiveram sua memória imaginária amputada da ordem significativa do mundo, já que "falar é existir plenamente para o outro" (FANON, 2008, p. 19).

Dessa deliberada exclusão, surgem, na contemporaneidade, movimentos sociais e artísticos que visam descortinar as múltiplas formas de violência simbólica sofridas por grupos que não se enquadram na cultura autorizada e legitimada pelos aparelhos ideológicos vigentes, como, por exemplo, o protagonismo da comunidade LGBT, das mulheres, dos negros e dos povos originários. As referidas formas de violência são responsáveis pela distinção entre aqueles que têm o direito à educação, à literatura, às artes e os que ficam à margem dos processos conformadores da dignidade humana. Mais do que isso, esses movimentos empreendem embates contra o sistema canônico, no intuito de inserir vozes, há muito silenciadas, no processo de autoria nos domínios literários.

Precisamos, então, delinear o que é e como se constitui a materialidade literária, sendo, ao mesmo tempo, uma necessidade, já que é inerente, e direito de todo ser humano. A respeito da desmistificação da literatura, geralmente representada pelas obras mais duradouras e distanciadas temporalmente, devemos compreendê-la

claramente como manifestação universal de todos os homens em todos os tempos. Não há povo e não há homem que possa viver sem [...] a possibilidade de entrar em contato com alguma espécie de fabulação. Assim como todos sonham todas as noites, ninguém é capaz de passar as vinte e quatro horas do dia sem alguns momentos de entrega ao universo fabulado. [...] E durante a vigília a criação ficcional ou poética [...] está presente em cada um de nós, analfabeto ou erudito, como anedota, causo, história em quadrinhos, noticiário policial, canção popular, moda de viola (CANDIDO, 2004, p. 174).

Considerando que a literatura seja, além de direito e necessidade, expressão artística tanto do meio erudito quanto popular, e até mesmo daqueles que não dominam a prática da escrita, cabe refletirmos sobre como, enfim, ela pode ser ferramenta humanizadora da sociedade e do sujeito. Nessa perspectiva, o ato de humanizar precisa estar conectado à constituição de uma sociedade justa, que compreenda, por exemplo, as lutas distintas das mulheres, dos negros 
e dos anônimos que buscam espaço para fazer sua voz significar, ao outro e a si. Humanização é, no sentido mais abrangente, um

processo que confirma ao homem aqueles traços que reputamos essenciais, como o exercício da reflexão, a aquisição do saber, a boa disposição para com o próximo, o afinamento das emoções, a capacidade de penetrar nos problemas da vida, o senso da beleza, a percepção da complexidade do mundo e dos seres, o cultivo do humor (CANDIDO, 2004, p. 180).

Ao contemplar esses valores essenciais, a materialidade literária assume sua função primordial de humanizar e aproximar sujeito e obra, autor e sociedade, leitor e sentidos. A partir do reconhecimento da literatura como construção criativa essencialmente humana, não é possível vinculá-la, obrigatoriamente, a um contexto acadêmico, uma vez que

tem os seus próprios métodos válidos, que não são sempre os das ciências naturais mas que, não obstante, são métodos intelectuais. Apenas uma concepção muito restrita de verdade pode excluir as conquistas das humanidades do domínio do conhecimento. Muito antes do desenvolvimento científico moderno, a filosofia, a história, a teoria do direito, a teologia e mesmo a filologia haviam elaborado métodos de saber (WELLEK; WARREN, 2003, p. 05).

Por meio da linguagem literária e seus mundos ficcionalmente figurados, podemos melhor conhecer o mundo e nós mesmos, reconhecer-mo-nos na história de personagens construídos e rememorados desde a realidade que conhecemos ou daquela que temos de desvendar. É, também, pelo texto literário que podemos inferir sobre valores transformadores ou reviver outros que deram origem ao que somos. Em suma, podemos organizar as narrativas que nos conformam no sistema sígnico do imaginário social, funcionalizando as nuances poéticas de nossa discursividade subjetiva.

\subsection{Poesia: expressão profundamente humana}

Ao entendermos o poema como materialização do discurso poético que submerge aos movimentos do imaginário, temo-lo como a concretização da subjetividade discursiva, isto é, o sujeito passa a ser também objeto do olhar sensível sobre o mundo e por ele é afetado. Em contrapartida, é preciso que ele se permita experimentar o fenômeno do devaneio. Assim, sem dúvida,

é com os devaneios da anima que o poeta consegue dar a suas ideias de animus a estrutura de um canto, a força de um canto. Portanto, sem devaneio de anima, como ler o que o poeta escreveu absorto num devaneio de anima? E assim eu me justifico de só saber ler os poetas em estado de devaneio (BACHELARD, 1996, p. 68, grifo do autor).

Os conceitos anima e animus propostos pelo autor configuram-se como um signo dual e coexistem em todo ser humano, relacionando-se ao seu estado de espírito. Anima refere-se à 
capacidade criativa e criadora e não estabelece compromisso com a realidade pragmática, enquanto animus é o elemento austero e simples, utilizado pela psiquê nas ações cotidianas.

A retomada da afirmação de que o poema não firma pacto com o conhecimento canônico suscita a reflexão sobre qual é, afinal, o seu propósito. De acordo com Wellek e Warren (2003, p. 35), “a poesia tem muitas funções possíveis. Sua função primordial e principal é a fidelidade à sua própria natureza”. Importante considerarmos, ainda, o modo de materialização da poesia. Além da escrita em versos e de seu agrupamento em estrofes, o poema nasce de uma imagem expressa pela metáfora, signo originalmente deslocado da ordem lógica da linguagem. Por conseguinte, é a imagem poética que instaura o tempo do poema, aquele que determina quais outras imagens serão construídas ao longo do texto e serão evocadas no sujeito afetado pelos sentidos do texto poético. Mais especificamente, a imagem poética

não está submetida a um impulso. Não é o eco de um passado. É antes o inverso: pela explosão de uma imagem, o passado longínquo ressoa em ecos e não se vê mais em que profundidade esses ecos vão repercutir e cessar. Por sua novidade, por sua atividade, a imagem poética tem um ser próprio, um dinamismo próprio. Ela advém de uma ontologia direta (BACHELARD, 1989, p. 183, grifo do autor).

O excerto aponta o dinamismo como um importante elemento constituinte da imagem poética e de sua significação na ordem fenomenológica, direcionando a poesia aos mais variados destinos, condicionados, tão somente, à sua ontologia. Nesse sentido, para criar um poema, além de permitir-se anima e aceitar o dinamismo das imagens poéticas, é preciso que o lirismo assuma a composição dessas imagens, significando-as e ordenando-as, em uma estrutura material. Com isso, entendemos que para

fazer um poema completo, bem estruturado, será preciso que o espírito o prefigure em projetos. Mas, para uma simples imagem poética, não há projeto, e não lhe é preciso mais que um movimento da alma. Numa imagem poética a alma acusa sua presença (BACHELARD, 1989, p. 187).

A partir da ideia de que a alma e o anima dão o primeiro sopro de luz a qualquer imagem poética, entende-se que essa, uma vez criada, atribui um novo e único sentido à poesia. Aliando-se ao sistema operatório da linguagem, a poesia adquire expressão e já não pode voltar a ser somente a imagem anterior ao sujeito e, dessa forma, para Bachelard (1989), os impulsos linguísticos que fogem à lógica ordinária da linguagem pragmática são pequenas manifestações do impulso vital da poesia.

Assim, por tratarmos a interdependência da imagem poética com a metáfora - figura de linguagem que materializa a imagem - entendemos que esse caráter metafórico é originado pela poesia e por ela também é reativado em cada manifestação poética. "A atividade poética busca uma relação intensa com o 'mundo-da-vida'” (BOSI, 1977, p. 111), por isso, o fazer poético carece de ser um direito inalienável de todo ser humano. É partindo dessa premissa que encaramos o poema, aceitando-o como um reduto de signos, imagens e subjetividade, força latente do imaginário, sem ignorar, entretanto, seu vínculo natural com o mundo da vida e tudo que tange a sua composição. Miramos, sobretudo, o poema como a atividade humana para 
refletir, liricamente, acerca das temáticas para as quais não encontra espaço no ambiente das narrativas estáveis. Buscamos, nessa ordem, descortinar a materialidade poética como arte, expressão e necessidade fundamentalmente humanas.

Nesse sentido, tomando-a como objeto de análise, "a poesia contemporânea pôs a liberdade no próprio corpo da linguagem. A poesia aparece então como um fenômeno da liberdade" (BACHELARD, 1989, p. 190) e, cada vez mais, fortalece-se em movimentos culturais imbuídos de preocupações sociais com os que vivem à margem dos espaços de discussões oficiais, incluindo aqueles que debatem sobre o que pode pertencer, de fato, aos domínios da literatura.

\section{Slam: campo de batalha da poesia feminina e palco aberto a disputas}

Para muito além da liberdade de expressão, tão debatida atualmente, também vem emergindo como necessidade de manifestação das vozes silenciadas historicamente a liberdade poética. Dentro desse grupo, encontra-se o potencial de voz das mulheres na contemporaneidade, que buscam meios para denunciar diversas das problemáticas vivenciadas, a partir de uma linguagem incisiva e de valorização das lutas vividas no passado, a fim de ocupar um espaço, dantes, legítimo apenas nas academias, editoras e demais meios e veículos culturais elitizados, com produção e consumo literários diretamente ligados à ordem hegemônica da cultura.

É prudente destacarmos, desse modo, a influência da poesia oral nas manifestações sociais e literárias largamente praticadas pela humanidade ao longo dos tempos. Isso porque a poesia é rítmica, tal como a própria vida, e a voz torna-se instrumento valioso na expressão de todo o seu conteúdo. Nesse sentido, Zumthor (1997) considera que a poesia é onde se ouve, ainda que confusamente, o eco de outras vozes do passado, que instituem costumes tão antigos quanto a voz humana e que se adaptam a cada geração.

Sob esse ponto de vista, visamos a apresentar as faces femininas do movimento social contemporâneo denominado Slam, iniciado em Chicago e que chegou ao Brasil no final da década de 2000. Tal movimento merece um estudo mais aprofundado, pois sua proposta é descentralizar a produção poética, privilegiando a voz e a vez de pessoas que não teriam oportunidade de serem ouvidas em meios convencionais de expressão literária, e, neste caso, das mulheres.

A fim de compreender melhor o alastramento desse movimento no Brasil, precisamos imergir na história do nascimento da poesia marginal e da Geração Mimeógrafo, que surgiram com força no mesmo período em que a ditadura militar calava implacavelmente as vozes contestadoras e os grupos sociais destoantes do perfil conservador da sociedade à época. No tocante à abordagem do Slam como manifestação literária e produção marginal, cabe considerarmos que tudo que

não se enquadra num padrão estabelecido ficou sendo marginal: cabelo comprido, sexo livre, gibi, gíria, rock, droga e outras bandeiras recentes que tipificam um fenômeno de rebeldia das novas gerações ocidentais 
denominado justamente contracultura (MATTOSO, 1981, p. 08, grifo do autor).

Tendo em vista a abrangência conceitual contida no termo marginal, faz-se necessário especificar que utilizaremos, ao longo deste estudo, o termo para designar as formas de se produzir poesia distantes e independentes das instituições que, convencionalmente, publicam e fundam a literatura. Consideramos, portanto, poesia marginal como hiperônimo das manifestações poéticas fora do sistema paradigmático e conservador, tanto na estrutura dos poemas quanto na linguagem empregada e nas temáticas desenvolvidas.

No acervo de temáticas abordadas pelas bandeiras da rebeldia atualmente, uma que vem sendo amplamente discutida é a do protagonismo feminino, cujas necessidades e interesses eram, até então, ignorados ou eufemisticamente recebiam menos importância pelas classes dominantes e pelas instituições da sociedade. Em se tratando da discussão sobre a equidade de direitos das mulheres e de outros grupos, é imprescindível destacarmos os espaços de debate legítimos e a dimensão da ressonância de suas vozes na sociedade. É justamente à guisa de exemplo desses espaços legítimos de debate, de expressão literária e de manifestação social que apresentamos a importância do Slam, concomitantemente à estrutura das batalhas de poesia com temática feminina e feminista.

O conceito de Poesia Marginal foi usado inicialmente por teóricos da literatura no período do Tropicalismo, na década de 1960, e, de acordo com Mattoso (1981), junto ao movimento Tropicália, as tendências musicais romperam as barreiras que delimitavam os estilos aplaudidos e produzidos pelas mais variadas faixas etárias. Isso fez com que os jovens se sentissem atraídos por aquilo que era ou que pudesse ser considerado poesia, justamente quando, por meio do AI-5, a censura recaía sobre a efervescência artística e sobre os jovens. Como consequência, começavam a surgir poetas e poesias furtivos, os que logo se tornaram conhecidos como marginais.

A poesia marginal e os poetas expoentes desse estilo contaram com outra alcunha bastante conhecida: a Geração Mimeógrafo. Tal título surgiu a partir do modo de impressão das obras produzidas por poetas cujas condições financeiras não permitiam que fossem impressas por editoras ou com acabamento mais rebuscado. Os escritores, portanto, mimeografavam seus textos, e o mimeógrafo passou a ser, dessa forma, equipamento indispensável ao ato de disseminar poesia.

Tanto o equipamento quanto o modo de impressão tornaram-se portas para o reconhecimento do contingente literário produzido por tal geração e

Prova disso é que após o destaque obtido pela poesia desses autores, especialmente em antologias e em estudos críticos, a maioria relançou muitos de seus livros, antes mimeografados, em grandes editoras. Ingressaram, assim, no campo literário brasileiro. Na verdade, utilizaram de uma inserção marginal para caminhar para o centro do sistema literário. Dificilmente os livros mimeografados por aquela geração gerariam efeitos no campo literário caso não tivessem sido inseridos em antologias e posteriormente acolhidos por críticos, jornalistas e professores universitários e publicados por grandes editoras (BRITTO, 2012, p. 125). 
Ainda que a proposição de estudos e aprofundamentos acerca da poesia marginal só tenham sido possíveis a partir da validação de seu valor por parte da crítica literária e das academias, destacamos que uma das grandes contribuições desse movimento é essencialmente a ousada ideia de que qualquer pessoa, mesmo nas mais precárias condições, possa produzir poemas, desde que a sensibilidade do ser se transponha à ideia de comercialização da literatura.

Em contraponto, não é sensato ignorarmos a imersão da sociedade nos parâmetros do sistema capitalista editorial, que, desde muito tempo, envolve a produção e a expansão do que é considerado literatura. Lembremo-nos aqui da organização preconizada por Martinho Lutero, na ocasião da divulgação de sua proposição reformativa da Igreja, além da definição das fronteiras nacionais europeias no século XVI. Desse modo, podemos considerar que o texto poético exerce, também, função de resistência discursiva, pois é segregado da vida pragmática das pessoas e dos discursos cotidianos. Ou seja, vai contra aquilo que visa se relacionar com os moldes capitalistas. De modo mais detalhado,

A poesia há muito que não consegue integrar-se, feliz, nos discursos correntes da sociedade. Daí vêm as saídas difíceis: o símbolo fechado, o canto oposto à língua da tribo, antes brado ou sussurro que discurso pleno, a palavra-esgar, a autodesarticulação, o silêncio [...]. Essas formas estranhas pelas quais o poético sobrevive em um meio hostil ou surdo, não constituem o ser da poesia, mas apenas o seu modo historicamente possível de existir no interior do processo capitalista (BOSI, 1977, p. 142).

Os estudos para compreender como e a partir de quais discursos são constituídos os cercos de resistência do gênero poético, nesse sentido, focalizam uma importante característica da poesia marginal: a polifonia. De acordo com Roman (1993), valendo-se de elementos da teoria bakthiniana, a polifonia é, essencialmente, a presença de múltiplas vozes proferindo diferentes textos que advêm e, ao mesmo tempo, são geradores de novos discursos. No contexto polifônico, destaca-se, ainda, o fato de que as vozes permanecem independentes e, portanto, compõem uma unidade de ordem superior à da homofonia, sem que seja a ela subordinada. Ao pensarmos a teoria proposta por Bakthin sobre polifonia no universo lírico, entendemos que as ressonâncias

se dispersam nos diferentes planos da nossa vida no mundo, a repercussão nos chama a um aprofundamento de nossa própria existência. Na ressonância, ouvimos o poema, na repercussão nós o falamos, pois é nosso. A repercussão opera uma revirada do ser. Parece que o ser do poeta é nosso ser. A multiplicidade das ressonâncias sai então da unidade do ser da repercussão. Dito de maneira mais simples, trata-se de uma impressão bem conhecida por todo leitor apaixonado por poemas: o poema nos prende por completo (BACHELARD, 1989, p. 187).

Nesse sentido, ao vislumbrarmos o Slam sob a ótica polifônica, depreendemos ser, em sua essência, um movimento sociocultural em que as diferentes vozes das mulheres poetas, ou slammers, encontram o cronotopo para fazerem reverberar seus múltiplos discursos por meio da partilha de poemas e lutas. A polifonia, assim, garante a amplificação dessas vozes para além de 
onde as narrativas sociais da ordem cultural sistêmica as colocaram.

A dinâmica das batalhas poéticas performativas do Slam muito se assemelha à empregada nas batalhas de rap, também popularizadas no Brasil, entretanto, a influência oral sobre a musical e a maior flexibilidade para a leitura ou declamação são as principais diferenças. No Slam, o corpo toma uma dimensão de significância coadunada às relações significantes da memória da palavra, em que a slammer assume a centralidade de sujeito que se enuncia e se narra desde uma condição propulsora da espiral de significação do imaginário. Nas batalhas de poesia, ainda, é possível que os poemas sejam lidos a partir de algum suporte impresso e não ocorre a preferência por textos inéditos ou construídos no momento de recitá-los. Ou seja, o que, de fato, significa é o deslocamento da palavra que estava à deriva na periferia ordinária do imaginário social e, agora, encontra eco e ressonância na pluralidade de vozes que revelam subjetivações outrora silenciadas.

O termo Slam, em tradução do inglês, significa algo como "batida", elemento que se aproxima do ritmo presente nas canções, nos versos de um poema, na contagem do tempo, nas fases da vida e da história. É o ritmo que determina a velocidade das informações e dos sentimentos apresentados nos poemas. É a própria percussão da poesia e "Nessa percussão, a imagem poética terá uma sonoridade do ser. O poeta fala no âmago do ser. Será necessário, pois, para determinar o ser de uma imagem, senti-la em sua repercussão" (BACHELARD, 1989, p. 184). Dessa maneira, o Slam trata com a latência íntima das poetas acerca de temas relevantes e vivenciados por elas, os quais se originam e se relacionam com situações, vivências, historicidade e condições atreladas ao ser mulher na contemporaneidade.

As batalhas de poesia feminina dividem-se em modalidades, como, por exemplo, "Slam das Minas", com poemas de autoria feminina e que são declamados somente por mulheres; "Slam Ventre Livre", que trata das lutas das mulheres pela equidade de gêneros, pelo direito ao empoderamento e à autoafirmação em meio ao patriarcalismo; "Slam do gozo", cujo tema está ligado à sexualidade e ao erotismo; dentre outros que surgem ou se associam aos temas supracitados.

Ao debruçarmo-nos sobre os estudos do Slam, encontramos o modo como as batalhas propiciam um novo espaço de produção e partilha do sensível poético, podendo abrir caminhos para descobertas no âmbito da autoafirmação e do reconhecimento a respeito das múltiplas lutas das mulheres pela conquista de espaço. Lutas que foram iniciadas no passado, mas que precisam ser ressignificadas no presente, a fim de que as gerações futuras possam habitar uma nova forma de sociedade, como observa Bachelard (1989), gestando um espaço onde mulheres e homens, crianças, idosos e jovens, com suas etnias e sexualidades diversas, tenham seus direitos validados e preservados, com equidade e dignidade.

\subsection{O espaço do Slam e das slammers na cultura contemporânea}

As performances do Slam ocorrem, em geral, nos espaços centrais das cidades, embora seja um movimento marginal, de acordo com as considerações já explicitadas. Isso porque, organizando-as em espaços centrais da urbe, as vozes oriundas da periferia são percebidas e reverberam na centralidade do poder. Essa localização também funciona como um facilitador 
de acesso ao público, para novas poetas e a propagação do evento. A fim de que o Slam aconteça, é necessário que as poetas se inscrevam em edições previamente divulgadas nas páginas das redes sociais, de acordo com a temática norteadora. Isso significa que no "Slam das Minas" ou no "Slam Ventre Livre", por exemplo, ocorrem batalhas em que apenas mulheres poderão se inscrever. Nas demais modalidades, as inscrições são abertas a quaisquer poetas cujos poemas contemplem a temática da edição.

A inscrição ocorre no local do evento, por meio da informação do nome ou pseudônimo da pessoa que competirá. Logo após as inscrições, são indicados os jurados, compostos por voluntários do público presente. A partir daí, constitui-se um mediador, que, proferindo um grito de guerra que identifique a temática da edição do Slam, dá início à batalha. Esse grito de guerra, por sua vez, é respondido pela plateia como forma de incentivar as slammers antes de cada declamação.

A performance das slammers, em geral, não pode ultrapassar o tempo máximo de três minutos ${ }^{4}$ por poema declamado, contando com dez segundos de tolerância. Caso ultrapasse, cada segundo implica na perda de um décimo da nota atribuída pelos jurados. Entretanto, não são os jurados que indicam a transgressão do tempo limite, tampouco fazem o desconto da nota. Para isso, é indicada uma outra pessoa, geralmente envolvida na organização da edição, que registra as notas atribuídas e os seus descontos, caso seja necessário, e, ao término das batalhas, revela a média das notas, apontando, assim, a slammer vencedora.

Essa forma de promover o destaque da poesia relaciona-se, diretamente, à democracia e ao exercício da cidadania, posto que trabalha com a ocupação de espaços públicos para as edições do evento. Contudo, também conecta-se à liberdade de expressão, especificamente, à expressão poética. A poesia que habita o espaço furtivo do Slam nada mais é do que a luta violentamente pacífica pela conquista de um espaço legítimo na sociedade, a fim de que a voz dos anônimos eco desde um patamar de audiência coletiva, porquanto a poesia "dos tempos modernos é [...] 'meio muda, meio articulada'. É força, é representação” (BOSI, 1977, p. 92).

A poesia é, nessa ordem, a ferramenta para que o público, os passantes, os jurados se identifiquem com a narrativa do imaginário da poeta, carregada de denúncias e, ao mesmo tempo, de esperança, conforme Bachelard (1989) sustenta na afirmação de que o poeta não confia ao público o passado da sua própria imagem, mas a sua história cria raízes imediatamente no público.

Entendendo, pois, que o Slam é resistência e ruptura das narrativas oficiais, cabe refletirmos sobre como elas afetam as pessoas que não são contempladas por esses discursos hegemônicos e sobre sua raiz. Nesse sentido, é necessário observar que

Desde o início do século XIX, a construção da história do mundo tem sido controlada pela Europa ocidental, que registrou sua presença no resto do mundo como resultado da conquista colonial e da Revolução Industrial. [...] O que caracteriza a postura europeia, assim como a de sociedades mais

\footnotetext{
${ }^{4}$ Apenas nas edições do "Slam do Trago" o tempo limite é menor, contando com trinta segundos para cada declamação e, no máximo, quinze segundos de tolerância devido ao maior número de inscrições para essa modalidade, que ocorre exclusivamente no Rio Grande do Sul.
} 
simples, é a tendência de impor a própria história ao mundo. Essa tendência etnocêntrica é extensão de um impulso egocêntrico na base de grande parte da percepção humana e se realiza pelo domínio de fato de muitas partes do mundo. Eu vejo o mundo necessariamente pelos meus olhos, não com os olhos dos outros (GOODY, 2013, p. 23, grifo do autor).

Para muitas pessoas, produzir efeitos de sentido a partir da sua relação subjetiva com o mundo não era possível até meados do século XX, essencialmente pela predominância das concepções etnocêntricas, heteronormativas e das que preconizavam os padrões europeus sobre quaisquer outras formas de cultura. Isso constituiu um palimpsesto narrativo que deu origem a uma sólida camada de preconceitos em relação não somente às mulheres e sua subjetividade, mas também às concepções que outras culturas tinham sobre tempo e espaço.

De acordo com Goody (2013), as noções espaçotemporais foram determinadas pelo Ocidente, sobrepujando os conceitos de espaço e tempo de outras culturas. Isso culminou na opressão do modo de vida de outras sociedades, como as que foram colonizadas e escravizadas no Brasil. Tal informação ganha importância nos tópicos propostos neste estudo pelo fato de, os estratos sociais que buscam seu espaço de expressão no Slam terem sua história conectada a alguma forma de violência oriunda da dominação imposta pelos parâmetros europeus e ocidentais.

A homogeneização das culturas propostas pelo Ocidente impacta diretamente na produção literária que, até então, só se tornava expoente quando advinda da superfície da - já mencionada - sólida camada de preconceitos. Em outras palavras, sabemos que

os estudos literários e a própria categoria de literário foram e são ainda, segundo alguns lugares teóricos, denominados por noções como a universalidade, expressa pela crença de que, a despeito da diversidade e multiplicidade do fenômeno literário, é possível construir uma poética universal, ou um discurso homogêneo, situando-se numa espécie de zona incontaminada da ideologia, conferindo-se-lhe um prestígio especial isolando-a de outras formas de discurso (LEITE, 2012, p. 142).

Em conformidade a essa percepção, questionar a composição do complexo canônico é confrontar aqueles que detêm o poder intelectual e que justificam sua dominação por meio da repetição e expansão de discursos que visam anular as diferenças entre as pessoas na tentativa de torná-las uma massa social volúvel e desprovida de autoria, protagonismo e cidadania. Não obstante, a cultura não é homogênea tampouco se propõe a isso, pois, consoante Wagner (2009), fosse ela algo absoluto e objetivo, o aprendizado de uma cultura ocorreria igualmente para todos. Entretanto, as pessoas possuem uma gama de predisposições e afeições distintas, de modo que o entendimento da cultura como inflexível e objetiva apenas poderá ter utilidade como uma espécie de "muleta".

O apagamento das noções locais de tempo e espaço, bem como a distorção das diferenças em pseudoigualdades forçam um conceito de proximidade entre os discriminados e os favorecidos, o que só intensifica a situação discrepante entre os dois grupos. De acordo com Bhabha (2011), há um recorrente problema no conceito de igualdade, pois o liberalismo pressupõe uma noção não diferencial relacionada ao tempo cultural, isto é, ao tentar naturalizar 
a diferença e corromper a noção de respeito, acaba por ignorar as temporalidades disjuntivas e fronteiriças existentes entre as culturas politicamente minoritárias.

Compreendendo que o Slam ocupa um tipo de entrelugar na cultura, precisamos saber, afinal, qual é o espaço das slammers nessa fissura recente da cultura contemporânea, visto que se trata de sujeitos não representados nas narrativas oficiais e que, pelo jogo poético, conquistam, pouco a pouco, visibilidade. Assim, percebemos que

A inscrição do sujeito pertencente a uma minoria, situada em algum lugar entre o visivel demais e o não visivel o bastante, nos faz voltar para o sentido atribuído [...] à diferença cultural, uma conexão intercultural, que se encontra além da demonstração lógica. E isso exige que o sujeito discriminado, mesmo no processo de sua reconstituição, se situe em um momento presente, que é temporariamente disjuntivo e afetivamente ambivalente (BHABHA, 2011, p. 86, grifo do autor).

A situação da mulher protagonista no Slam e marginalizada de muitas maneiras nos processos sociais é carregada da referida ambivalência pelo fato de que se anseia, no embate social, determinada postura no enfrentamento das problemáticas políticas, sociais, culturais e identitárias no presente, a fim de conquistar a sua visibilidade. Essa condição é concebida pela sociedade não como sendo elemento universal, mas julgada como elemento específico da cultura. Portanto, frisando que o Slam é um movimento bastante recente, a conquista daquilo que ainda não é aceito faz da slammer uma habitante temporária de um entre-espaço imaginário, o que Bhabha define como sendo o entrelugar da cultura. Ainda consoante o autor, "O sujeito ou a comunidade discriminada ocupam um momento contemporâneo que está para sempre retardado e prematuro, em termos históricos (BHABHA, 2011, p. 86).

Durante o desenvolvimento das batalhas, o Slam torna-se a casa das poetas; o reduto e a proteção de que precisam para sentir a força que têm e externá-la por meio da linguagem poética, uma vez que a palavra redimensiona o estar no mundo e sistematiza a operação anímica da significação do corpo feminino. Mesmo sabendo que apenas uma slammer vence em cada edição, todas partilham da vitória maior, que é a reverberação da arte produzida na casa. Essa nova atribuição de sentido ao espaço público materializado pelo movimento sociocultural ratifica a ideia de que "todo espaço verdadeiramente habitado traz a essência da noção de casa" (BACHELARD, 1989, p. 200). Na solidez da casa, encontram abrigo e espaço para quinquilharias de que não podem se desfazer, lascas de imagens que arrastam memórias significantes. A casa é lugar construído pela linguagem para atenuar as intempéries do tempo, sítios que temos como segurança de regresso quando o caminho é feito de muitas voltas. A casa é, pois, aconchego da memória, arestas que orientam o sujeito para estar no mundo.

Assim, conformados pelo pensamento de Bachelard (1989), podemos considerar que, ao conjurar as lembranças da casa, as slammers agregam valor onírico e abandonam sua face historiadora, porque são poetas constituídas de animus e anima. No porão e no sótão do corpo poético, resgatam valores da consciência e da inconsciência. Se pensarmos em Bachelard (1989):

O próprio sonhador sonha racionalmente; para ele, o telhado pontiagudo corta as nuvens. Todos os pensamentos que se ligam ao telhado são claros. No 
sótão, vê-se, com prazer, a forte ossatura dos vigamentos. Participa-se da sólida geometria do carpinteiro. Para o porão também encontraremos, sem dúvida, utilidade. Nós o racionalizaremos enumerando suas comodidades. Mas ele é em primeiro lugar o ser obscuro da casa, o ser que participa das potências subterrâneas. Sonhando com ele, concordamos com a irracionalidade das profundezas (BACHELARD, 1989, p. 209, grifo do autor).

No sótão, a poeta organiza os utensílios para o seu labor: o vocabulário, a estrutura, a voz, o ensaio, bem como o corpo. Já no porão, vislumbra feixes desordenados da sua arte: a performance, o sentimento, o gaguejar, a metáfora, a expectativa da reação do outro. Sótão e porão são, substancialmente, dois espaços que precisam ser revisitados em cada edição de Slam, pois lá se encontram as ferramentas necessárias para uma batalha violentamente lírica, um embate entre o fenômeno poético e a dureza da realidade cotidiana. É nesse jogo que produzem o efeito de sentido de centralidade do marginalizado.

A casa sobre a qual discorremos é essencialmente extensão do corpo do sujeito, conforme a sensível afirmação de que "Escrevemos com o espírito. Falamos com o corpo" (LAFERRIÈRE, 2011, p. 11). Falta-nos, então, ponderar sobre outro espaço de extrema importância na casa, onde é possível fechar as cortinas e privilegiar a intimidade do ser: o quarto. É no quarto que o sujeito se despe das amarras e cascas sociais e sente o espírito livre da autoria. O quarto é o espaço legítimo da subjetividade, porquanto não precisa ser dividido como área social. Ele permite ao sujeito experimentar-se poeta, criar e vivenciar a sua obra sem o medo da censura. Ao considerarmos o quarto como ninho do processo de autoria, de acordo com Bachelard (1989), a casa torna-se psicologicamente confusa, uma vez que seus refúgios solitários relacionam-se ao quarto e os espaços, para uso dos seres dominantes, relacionam-se à sala, respectivamente.

Devido a essa relação conflituosa que ocorre na casa da slammer, é preciso encorajá-la a compartilhar nos espaços comuns a materialidade de sua erma autoria. É preciso, ainda, que toda poesia e toda arte produzidas nos espaços íntimos do devaneio sejam levadas e apreciadas nas salas, por mais imponentes que sejam. Sabemos que os espaços periféricos às grandes salas do mundo não deixarão de existir, porém movimentos como o Slam batalham a fim de que o acesso a elas seja franco a todos aqueles que desejem ocupá-las. Trata-se, pois, de um movimento que coloca em marcha o deslocamento do processo enunciativo, o que possibilita a relativização de espaços de poder.

\section{Considerações finais}

Ao largo deste estudo, propusemo-nos a estabelecer uma relação entre literatura, poesia e protagonismo das mulheres, a partir do Slam. Para tanto, apresentamos os elementos fundamentais que compõem o movimento e que o articulam ao espaço e à condição contemporâneos da mulher, enfocando o processo de autoria das poetas, as slammers.

É indispensável considerarmos o Slam à luz de uma significação para além de um movimento sociocultural e compreendê-lo, sobretudo, como resistência às formas de opressão e discriminação impostas ao ser mulher. Desde esse olhar, a poeta apropria-se das armas que tem 
e, no campo de batalha da poesia, torna-se uma slammer, atrelando, performaticamente, animus e anima, palavra e corpo, no intuito de constituir um processo de redenção enunciativa do sujeito deslocado. Para tanto, a poeta utiliza a voz a fim de se autoafirmar ou a empresta para representar e denunciar feridas sociais daquelas mulheres cujo acesso à sala, seja pelas narrativas íntimas seja pelas narrativas sociais, ainda se encontra obstado.

Partindo da premissa de que a literatura é um direito de todos, posto que é uma construção humana, propor reflexões torna-se necessário também quando percebidas restrições a seu acesso e universalização. Isso porque a função humanizadora das artes permite que seja possível valermo-nos delas, a fim de questionarmos os paradigmas, colocarmo-nos no lugar do outro sem a atitude viciosa de narrá-lo. Entender o fenômeno artístico é entender a necessidade que cada sujeito tem de colocar-se como narrador de sua história, de centralizar sua enunciação. Dessa forma, acreditamos que é pela linguagem que nos movimentamos como fenômeno humano para compreender a memória social e sua significação na ordem artística do sujeito. É, pois, a palavra enunciada que carrega em si uma rede de significação, a qual centraliza e marginaliza culturas constituintes da mesma ossatura antropológica. O Slam, nesse sentido, desempenha papel fundamental à valorização e ao desvelamento de vozes historicamente estabilizadas à margem da sociedade. E mais, cumpre dois papéis na ordem do sistema literário: relê, pela poesia, a oficialidade histórica e concede voz àqueles a quem a história reservou a afonia.

\section{Referências}

BACHELARD, G. A poética do devaneio. São Paulo: Martins Fontes, 1996.

BACHElARD, G. A Poética do espaço. São Paulo: Martins Fontes, 1989.

BHABHA, H. O entrelugar das culturas. In: COUTINHO, E. (org.). O bazar global e o clube dos cavalheiros ingleses. Textos seletos. Rio de Janeiro: Rocco, 2011.

BOSI, A. O ser e o tempo na poesia. São Paulo: Cultrix. Ed. da Universidade de São Paulo, 1977.

BRITTO, C. C. Mulheres nos interstícios de uma "geração mimeógrafo": itinerários de Ana Cristina César. Revista Eletrônica Literatura e Autoritarismo - Dossiê, Maio de 2012 - ISSN 1679 849X. Disponível em: 〈http://w3.ufsm.br/grpesqla/revista/dossie07/RevLitAut_art05.pdf〉. Acesso em: 30 mai. 2019.

CANDIDO, A. O direito à literatura. In: Vários escritos. 4. ed. São Paulo: Duas Cidades, 2004.

CASSIRER, E. Linguagem e Mito. 3. ed. São Paulo: Perspectivas, 1992.

ECO, U. Sobre a literatura. Rio de Janeiro: BestBolso, 2011.

FANON, F. Pele negra, máscaras brancas. Salvador: EDUFBA, 2008.

GOODY, J. O roubo da história. Como os europeus se apropriaram das ideias e invenções do Oriente. 2. ed. São Paulo: Contexto, 2013.

JAKOBSON, R. Linguística e comunicação. São Paulo: Cultrix, 2007.

LAFERRIÈRE, D. País sem chapéu. São Paulo: Editora 34, 2011. 
S.

LEITE, A. M. Oralidades e escritas pós-coloniais. Estudos sobre literaturas africanas. Rio de Janeiro: EdUERJ, 2012.

MATTOSO, G. O que é Poesia Marginal. 2. ed. São Paulo: Editora Brasiliense, 1981.

RANCIÈRE, J. A partilha do sensivel. São Paulo: Editora 34, 2014.

WAGNER, R. A invenção da cultura. São Paulo: Cosac Naify, 2009.

WARREN, A; WELLEK, R. Teoria da literatura e metodologia dos estudos literários. São Paulo: Martins Fontes, 2003.

ZUMTHOR, P. Introdução à poesia oral. São Paulo: Hucitec, 1997.

Recebido em: 20/08/2019

Aceito em: 07/11/2019 